\title{
Radiotherapy and wound healing: Principles, management and prospects (Review)
}

\author{
MATTHIAS GIERINGER, JAN GOSEPATH and RAMIN NAIM \\ Dr Horst Schmidt Klinik, D-65199 Wiesbaden, Germany
}

Received January 25, 2011; Accepted March 30, 2011

DOI: $10.3892 /$ or.2011.1319

\begin{abstract}
Radiation therapy is a major therapeutic modality in the management of cancer patients. Over $60 \%$ of these patients receive radiotherapy at some point during their course of treatment and over $90 \%$ will develop skin reactions after therapy. Problematic wound healing in radiation-damaged tissue constitutes a major surgical difficulty and despite all efforts, irradiated skin remains a therapeutic challenge. This review provides an overview of the fundamental principles of radiation therapy with regards to the wound healing in normal and irradiated skin. Furthermore, it presents techniques that describe how to prevent and manage skin side effects as well as prospects that may improve cutaneous wound repair in general and in irradiated skin.
\end{abstract}

\section{Contents}

1. Introduction

2. Fundamental principles of radiation therapy

3. Principles of wound healing

4. Wound healing in irradiated skin

5. Prevention and therapy of skin reactions

6. Prospects

7. Conclusions

\section{Introduction}

For almost one hundred years, radiation therapy has been used as a cancer treatment (1). Many low-dose treatments cause minimal or no side effects. Elevation to higher doses causes varying side effects during the course of treatment (acute side effects) (2). In the months or years following treatment, longterm side effects are observed (3). Cumulative side effects

Correspondence to: Dr Matthias Gieringer, Dr Horst Schmidt Klinik, Ludwig-Erhard Str. 100, D-65199 Wiesbaden, Germany E-mail: mkgieringer@gmail.com

Key words: radiotherapy, wound healing, keloid, scaring, fibroblasts appear after re-radiation (4). Skin irritation is the most frequent acute side effect (5). Fibrosis represents a typical long-term side effect and causes severe surgical difficulties (6). Wound repair of the skin is one of the most complex processes recognized and is characterized by the interaction between many processes and factors that occur in a precise sequence in the different layers of the skin. The coordination of these processes occurs through communicating proteins known as growth factors and cytokines. Abnormal wound healing is a typical result of the irradiated skin. It is the comprehension of the fundamental molecular principles regarding both normal and disturbed wound healing that currently provides effective therapeutic options $(7,8)$. This article discusses the fundamental principles of radiation therapy and wound healing in normal and irradiated skin, thereby elucidating emerging surgical difficulties as well as prospects in treatment.

\section{Fundamental principles of radiation therapy}

The radiotherapeutic approach for the eradication of malignant cells was first introduced during the late 19th century. Today radiotherapy is used as the primary therapy using combinations of surgery, chemotherapy hormone therapy, therapy with antibodies or a mixture of all strategies. Most cancer types can be treated with radiotherapy. Radiotherapy can be given either as a curative modality, adjuvant, or as a palliative treatment. Several biological and technical factors are taken into account when planning radiotherapy.

Techniques. Ionizing radiation is energy sufficiently strong enough to remove an orbital electron from an atom. This radiation can have an electromagnetic form, such as a highenergy photon or a particulate form, such as an electron, proton, neutron or an $\alpha$ particle (9). The most common form of radiation used in practice today is the high-energy photon which is also known as external beam radiotherapy (10). Photons that are released from the nucleus of a radioactive atom are known as gamma-rays. When photons are created electronically, as in a clinical linear accelerator, they are known as $\mathrm{X}$-rays. After penetrating the tissue, the particles begin to ionize surrounding molecules. Stereotactic radiosurgery uses focused radiation beams targeting a well-defined tumor using extremely detailed imaging scans (11). The therapy pinpoints high doses of radiation directly on the cancer in a shorter amount of time than traditional treatments. Particle therapy is 
a form of external beam therapy using beams of energetic protons, neutrons, or positive ions for cancer treatment. The most common type of particle therapy is proton therapy. Proton therapy achieves significant improvements in the probability of local control over conventional radiotherapy. Because of the increased precision, proton therapy is also used to reduce unwanted side effects by limiting the dose to the normal tissue. Brachytherapy can be used for temporary or permanent placement of radioactive sources and procedures can be performed with either temporary or permanent implants (13). Radioisotope therapy is primarily a method to eradicate disseminated tumor cells and small metastases, while bulky tumors and large metastases have to be treated surgically or by external radiation therapy. The radioisotopes are delivered through infusion or ingestion (14).

Mode of action. Radiation damage is a complex multi-faceted biological effect. It is assumed that radiation damage occurs within the DNA, and two types of damage-formation processes, both of which lead to cell lethality, may be postulated. Type A damage occurs when adjacent DNA strands are broken as a result of a single ionizing event. Type $B$ damage results from an interaction between two proximal single-strand breaks created in separate ionizing events. The individual single-brand breaks (e.g., the precursors to Type B damage) are assumed to be potentially repairable and, hence, sublethal. It thus follows that if the damage from the first sublethal event is repaired before the second event occurs, there will be no lethality (15). Several various normal tissue damage end-points are known: cell-cell interactions, cell differentiation, extracellular matrix remodelling, cytokine and growth factor secretion, clonogenic cell survival, vascular damage, chromosomal aberrations and DNA repair (16). The damage of DNA is caused directly by ionizing the atoms which make up the DNA chain. It can also be a result of indirect ionization by ionization of water, forming free radicals, which then damages the DNA. In the most common forms of radiation therapy, most of the radiation effect is through free radicals (17). Local tumor recurrence in the radiated field is often implicated as a primary cause of treatment failure following potentially curative radiation therapy for locally advanced solid tumors (18). Several treatmentspecific factors (e.g., total radiation dose, dose per fraction, overall treatment time) and patient-specific characteristics (e.g., disease stage, histology, performance status) are known to influence the probability of local tumor control by radiation therapy $(19,20)$. It is well known that the biological response to radiotherapy influences the outcome of radiation therapy; e.g., clonogenic cell growth can occur following fractionation, and if the cancer is growing exceedingly fast then it may expand between each daily fraction of treatment. The microenvironment of solid tumors is hypoxic compared with normal tissue, and this hypoxia is associated with decreased radiosensitivity (21). Thus, the specific and dominant factor(s) leading to disease recurrence in a particular patient may not easily be inferred.

Side effects. Normal body tissue varies in its response to radiation. The most sensitive cells to radiation therapy are those that divide rapidly. Early side effects are usually gone within a few weeks after treatment. Late side effects are those that take months or years to develop. They are often permanent.
The most common side effects of radiation are skin reaction and fatigue (22). Other, less common side effects are: hair loss, nausea and vomiting, diarrhea, loss of appetite and myelosuppression. Fibrosis is a common late side effect and can lead to functional loss and unwanted cosmetic results, a loss of self-esteem and a diminished quality of life (23). Very rare side effects are lung fibrosis and secondary cancers $(24,25)$. The first type of cancer documented as being associated with exposure to ionizing radiation was skin cancer, which was reported only 7 years after the discovery of X-rays (26). Patients undergoing radiotherapy display a large patient-to-patient variability in their risk of developing tissue reactions. The ultimate reason for these different reactions is a matter of intensive research.

\section{Principles of wound healing}

The three phases of tissue repair: inflammation, tissue formation, and tissue remodelling. Wound healing of the tissue follows a specific time sequence. The very complex repair processes are sub-divided into three phases that overlap in time and space.

Phase I: inflammation. The first of these phases is called the exudative phase or phase of physiological inflammation and it takes place within the first three days post injury. Immediately after the damage has taken place hemostasis is achieved by the formation of a platelet plug (27). Platelet cells are present in the highest numbers shortly after a wound occurs. They release and activate transforming growth factor $\beta$ (TGF- $\beta$ ) and platelet-derived growth factor (PDGF), which act as chemotactic agents in the recruitment of inflammatory cells, epithelial cells and fibroblasts (28). Growth factors in general are crucial in all three phases of wound healing. Emphasizing their importance, a subsequent chapter is dedicated to these peptides. Platelets also release proinflammatory factors like serotonin, bradykinin, prostaglandins, prostacyclins, thromboxane, and histamine which serve a number of purposes, including to increase cell proliferation and migration to the area and to cause blood vessels to become dilated and porous (29). This causes rubor, which is one of the classic signs of inflammation. Tumor and calor develop as egress of plasma protein and fluid into the interstitial space occurs. Dolor is sensed as prostacyclin, prostaglandin A and prostaglandin E act on peripheral nociceptors. The formation of the platelet plug is followed by the formation of a fibrin matrix, which then becomes the scaffold for infiltrating cells. A few hours after injury, granulocytes, macrophages and lymphocytes move into the affected area in order to remove dying tissue and to prevent ongoing infection. The second step within the phase of inflammation begins. Polymorphonuclear leukocytes (PMNs) now become the predominant cells in the wound, with especially high numbers on the second day. Their nucleus is so deeply lobated or divided that the cell looks like it has multiple nuclei (30). In addition to the above mentioned growth factors and kinins, cells are also attracted by fibronectin. Fibronectin is an extracellular matrix glycoprotein (31). It is secreted primarily by fibroblasts which secrete proteases, including matrix metalloproteinases that digest the plasma fibronectin, and then secrete cellular fibronectin. The PMNs are activated by the proinflammatory cytokines IL- $1 \beta$, tumor 
necrosis factor- $\alpha$ (TNF- $\alpha$ ) and interferon- $\gamma$ (IFN- $\gamma)$ (32). TNF is a cytokine, which is produced mainly by macrophages, lymphoid cells, mast cells and fibroblasts. IFN- $\gamma$ was originally called macrophage-activating factor. Its main function is to increase immunity against viral and intracellular bacterial infections and to control tumor growth. PMNs themselves phagocytize debris and bacteria and kill bacteria by releasing antimicrobial substances like reactive oxygen species, cationic peptides, eicosanoids as well as free radicals. In addition, they clean the wound by secreting proteases like elastase, cathepsin G, proteinase 3, and urokinase-type plasminogen activator (33). Usually they undergo apoptosis or are degraded by macrophages. Furthermore, helper T-cells secrete interleukin-2 (IL-2). Elevation of IL-2 causes further T-cell proliferation to augment the immunogenic response, to increase inflammation and to boost vasodilatation and the activity of macrophages. The role of particular T-cell subsets during repair requires further investigation. About two days after injury, macrophages are the predominant cells in the wound. Monocytes will have entered the wound and matured into macrophages. Macrophages are thought to be crucial for coordinating later events in the response to injury, as they phagocytize bacteria and damaged tissue. In addition, they release IL-1 and basic fibroblast growth factor (bFGF) (34). They are stimulated by the hypoxia in the wound and they induce angiogenesis by releasing IL-1. bFGF is a chemotactic and mitogenic factor for fibroblasts and endothelial cells. Macrophages effectively push the whole process one step forward. Nevertheless, the importance of neutrophils and macrophages is not completely understood. When the inflammation phase ends, fewer inflammatory factors are secreted and the numbers of neutrophils and macrophages decrease. This indicates that the second phase of normal wound healing is underway. An excessive or prolonged inflammatory response results in increased tissue injury and poor healing. Successful wound repair requires the coordinated expression of inflammation as well as the resolution of inflammation (32).

Phase II: tissue formation. The phase of proliferation (formation of granulation tissue), occurs in the fourth to seventh day after the injury. It is characterized by angiogenesis, the proliferation of fibroblasts and the formation of collagen, and by the proliferation and migration of keratinocytes, which results in complete wound closure. Angiogenic growth factors activate receptors present in endothelial cells of pre-existing blood vessels. The activated endothelial cells then begin to release proteases that degrade the basement membrane, allowing endothelial cells to escape from the original vessel walls. Important angiogenic growth factors are FGF, VEGF, PDGF and TGF- $\beta$. Fibroblasts soon become the dominant cell type. The apex occurs 1-2 weeks post injury. They accumulate simultaneously with angiogenesis. In the first two or three days post injury, fibroblasts mainly migrate and proliferate, and they later become the main cells that lay down the collagen matrix in the wound site (35). Thereby, fibroblasts utilize fibrin to migrate across the wound, subsequently adhering to fibronectin. Fibroblasts then produce the ground substance. This is the term for the non-cellular components of the extracellular matrix (ECM) and it is primarily composed of the glycosaminoglycans, hyaluronan, proteoglycans and glycoproteins. It does not include collagen. Granulation tissue is constantly growing in the wound bed. This tissue contains new blood vessels, fibroblasts, inflammatory cells, endothelial cells, myofibroblasts and the components of ECM. The ECM is essential for wound healing and fibrosis and contains proteoglycans, such as heparin sulfate and chondroitin sulfate in addition to hyaluronic acid and fibers like collagen and elastin (36). ECM has many functions, such as providing support and anchorage for cells, segregating tissues from one another, regulating intercellular communication and releasing and bailing growth factors. When conditions in the wound are changing, ECM is able to deplete these depots according to requirements (37). Subsequently, fibronectin allows cells and agents to move through the ECM (38). Macrophages simulate fibroblasts to differentiate into myofibroblasts. They are contractile cells and bring the edges of a wound together. Basal keratinocytes proliferate from the wound edges ceasing movement when they meet in the middle. Fibroblasts secret collagen and deposit it at the bottom of the wound. If the contraction continues for too long, it can lead to disfigurement and loss of function. Decreasing hyaluronic acid levels while increasing chondroitin sulfate levels in the ground substance, hinders fibroblast migration and proliferation (39). At this time fibroblasts begin to undergo apoptosis, converting granulation tissue from an environment rich in cells to one that consists mainly of collagen. The maturation phase of wound healing begins.

Phase III: maturation and remodelling. This phase begins about two weeks after injury and lasts for a year or more. Most endothelial cells, macrophages and fibroblasts undergo apoptosis or exit the wound. The temporary scar mostly consists of collagen and extracellular matrix. The acellular matrix is actively remodelled from a mainly type III collagen backbone to one predominantly composed of type I collagen (40). Type I collagen is stronger. Furthermore, the originally disorganized collagen fibers become rearranged, cross-linked, and aligned along tension lines. This process is carried out by matrix metalloproteinases (MMPs) which are secreted by fibroblasts, macrophages and endothelial cells (41). MMPs are endopeptidases and play an important role not only in wound healing, but also in other physiological and pathological processes such as morphogenesis, angiogenesis, tissue repair, cirrhosis, arthritis and metastasis (42). When the phase of maturation is completed, a scar will have appeared as the typical end-point of normal mammalian tissue repair.

Growth factors. The complex interactions between the different components present during wound healing are mediated by interacting molecules, both mediators and receptors, known as growth factors and cytokines. These molecules are synthesized and secreted by many types of cells involved in tissue repair, including platelets, inflammatory cells, fibroblasts, epithelial cells and vascular endothelial cells (43). They are crucial for the initialization, the feeding and the regulation of wound healing and attach to specific membrane-attached receptors and activate them. This in turn activates an intracellular pathway, which proceeds to regulate gene expression and the cycle of cell progression. The terms, growth factor and cytokine do not have biological significance, but rather represent how these molecules have historically been defined. Growth factors typically act as signaling molecules between cells. 
Autocrine, paracrine and endocrine effects are distinguished. There is a need for high levels of growth factors and cytokines as key regulators during the healing process, but abnormal growth factor expression may lead to abnormal wound healing. It is possible that the timing and pattern of cytokine response may be more important than the magnitude of their expression (44). In the last two decades, an increased and accelerated level of knowledge on growth factors and cytokines involved in wound healing has been reached. However, it is beyond the scope of this article to explore this background knowledge. Subsequently, the listed growth factors are the key factors in wound healing $(45,46)$.

Vascular endothelial growth factor (VEGF). VEGF is secreted by keratinocytes, macrophages and fibroblasts (47) and is induced by the local tissue environment, such as hypoxia or nitric oxide production. The level of VEGF steadily increases post injury. VEGF is a potent angiogenic factor and is important for the production, differentiation and permeability of blood vessels and lymphatic endothelial cells (48).

Transforming growth factor $\beta$ (TGF- $\beta$ ). TGF- $\beta$ is released by platelets, macrophages and fibroblasts. It is a member of a large family of structurally-related factors with varying activities and is found in three isomers, 1-3. The most important activities include fibroblast migration, maturation and the synthesis of extracellular matrix $(49,50)$. TGF- $\beta 1$ appears to play an important role in the metabolism of collagen $(51,52)$. TGF- $\beta$ is present in most cell types, especially in thrombocytes. Isoforms 1-3 have varying effects depending on the cell type in which they are found. Antidromic effects are possible in cell proliferation and differentiation (53). TGF- $\beta 1$ and $-\beta 2$ are pro-fibrotic and TGF- $\beta 3$ is believed to be anti-fibrotic (54). In experiments with rats, the neutralization of TGF- $\beta 1$ and $-\beta 2$ with antibodies combined with the activation of TGF- $\beta 3$ has prevented the formation of scar tissue (55). TGF- $\beta 1$ stimulates VEGF (56), decreases MMP activity and increases the activity of endogenous inhibitors of MMP expression, which may favour collagen accumulation and scarring.

Epidermal growth factor $(E G F)$. EGF is primarily secreted by activated macrophages and keratinocytes. It was first found in the mouse submandibular gland. EGF has highly similar structural and functional characteristics to TGF- $\alpha$ and to the hepatocyte growth factor/scatter factor (HGF/SF). Members of this protein family act by binding to the epidermal growth factor receptor (EGFR) on the cell surface and stimulate the intrinsic protein-tyrosine kinase activity of the receptor. The tyrosine kinase activity leads to many biochemical changes within the cell, including an increased glycolysis and protein synthesis. It also increases the expression of certain genes, including that for EGFR that ultimately lead to cell proliferation. It is mitogenic for keratinocytes and fibroblasts and increases granulation and tissue formation in the wound bed. EGF-therapy with monoclonal antibodies plays an important role in cancer therapy (57).

Platelet-derived growth factor (PDGF). PDGF is produced by platelets, macrophages, vascular endothelium, fibroblasts and keratinocytes $(58,59)$. PDGF is released by platelets soon after injury, and recruits fibroblasts and macrophages. It stimulates collagen and proteoglycan synthesis. PDGF is involved in all stages of wound healing and influences the growth and the function of various mesenchymal cells (60).
Furthermore, PDGF stimulates the production of collagenase and the components of the extracellular matrix, fibronectin and hyaluronic acid. In contrast to VEGF, PDGF has a prolonged expression during scar formation, but disappears quickly in fetal wounds (61).

Fibroblast growth factor. The fibroblast growth factors (FGFs) are a protein family of 20 heparin-binding growth factors. FGFs are produced by fibroblasts, endothelial cells, smooth muscle cells, chondrocytes and mast cells, and are secreted by macrophages and endothelial cells. FGF induces angiogenesis and epithelialization through the induction of fibroblast and keratinocyte proliferation and migration, endothelial cell growth and migration, and collagen remodelling. FGF additionally prevents wound contraction (62). FGF7, also called keratinocyte growth factor (KGF), is the best known member of the group, responsible for keratinocyte regulation and maturation. FGF family members enhance the duplication and differentiation of many mesenchymal cells, including fibroblasts, muscle cells and chondrocytes.

Hepatocyte growth factor/scatter factor $(\mathrm{HGF} / \mathrm{SF})$. HGF/SF is secreted by vascular smooth muscle cells and fibroblasts. HGF was originally identified in 1984 as a mitogen of primary cultured hepatocytes. SF was identified in 1985 as a fibroblastderived epithelial motility factor. Subsequent characterization revealed $\mathrm{SF}$ to be identical to $\mathrm{HGF}$, with c-Met as the receptor (63). HGF/SF induces the expression and synthesis of MMPs. It enhances endothelial cell survival and renders vascular endothelial cells resistant to apoptosis (64). By increasing the expression of VEGF, angiogenesis is also increased. Zhu et al (65) induced the overexpression of HGF in vascular smooth muscle cells. This led to the increased migration and proliferation of endothelial cells, thus demonstrating the crucial role of HGF in the re-epithelialization of injured blood vessels (65). We have demonstrated the presence of modified HGF/SF expression in normal and radiated skin and in keloids. The strongest expression was found in keloids, whereas the lowest expression was found in irradiated skin (unpublished data).

Wound-healing disorders. The ideal end-point of wound healing of the skin would be total regeneration, with the new tissue having the same structural, aesthetic, and functional attributes as the original uninjured skin, but only fetal wounds heal in this way. If the normal continuum of wound healing is disturbed, healing may lead to either a chronic wound (ulcer) or to pathological scarring and extensive fibrosis. In general, chronic wounds can be segmented into the categories of venous, diabetic and pressure ulcers. Major pathophysiological factors that lead to chronic wounds are ischemia and bacterial colonization. Ischemia causes tissue to become inflamed and cells to release factors that attract neutrophils, such as interleukins, chemokines, leukotrienes, and complement factors (66). Bacterial colonization prolongs inflammation and damages tissue. This leads to a greater number of neutrophils entering the wound site. Neutrophils release inflammatory cytokines and enzymes that damage cells so that chronic wounds have higher levels of inflammatory and proinflammatory cytokines (IL-1, TNF and IL-6) compared to acute wounds (33). Exudates from non-healing wounds contain elevated levels of proteolytic enzymes, like elastase from polymorphonuclear granulocytes (PMN elastase), reactive 
oxygen species (ROS) and reactive nitrogen species (RNS). The overproduction of proteolytic enzymes leads to reduced concentrations of growth factors and proteinase inhibitors, resulting in an imbalance between the processes of degradation and remodelling. Boundless proteolytic activity caused by ongoing inflammation seems to be one of the main pathomechanisms of non-healing wounds (67). In comparison with the total prevalence of the above mentioned categories of chronic wounds, the prevalence of chronic wounds caused by ionizing radiation is quite rare. However the myriad of problems for patients and for surgeons can also be tremendous.

\section{Wound healing in irradiated skin}

Early skin reactions after radiotherapy are usually moderate, but over $90 \%$ of patients treated with radiotherapy develop skin reactions (68). These reactions appear in the early stages as erythema and as dry desquamation. If no infection occurs, re-epithelialization will begin within 10 days. Within two months, edema and inflammatory exudates will subside, and an area of brown pigmentation will be seen (69). Moist desquamation is characterized by a painful peeling skin with exposure of the dermis, exudate production and ulceration. Moist desquamation is observed in $<10 \%$ of patients and is dose-dependent (70). Ideally, surviving germinal cells regenerate to repopulate the epidermis and allow for healing. However, when this repopulation fails, an acute ulcer in radiated skin will occur. Since the introduction of megavoltage linear accelerators, skin reactions rarely deteriorate to the ulceration stage, because the maximum deposited dose to the skin is at 0.5-4 cm below. One year after radiation, the epidermis will appear dry, thin, and semi translucent. Hair follicles and sebaceous glands are usually absent. Fibrosis of the skin is present. The lymphatics are absent or blocked by fibrous tissue. Myocytes develop vacuoles and the muscles become scarred containing very few vessels. Years after radiation therapy, delayed ulcers and malignancies may occur. Delayed ulcers are more common than acute ulcers and may exist for several years. Commonly, the late skin reaction is characterized as fibrosis, atrophy, contraction, induration and a dose-dependent decrease in wound tensile strength. Poor wound healing can even lead to death, which may be from carotid artery rupture or to prolonged morbidity from fistula formation, wound dehiscence, skin flap reconstructive failure, and skin necrosis. Any localized trauma, surgery or infection to the irradiated skin can lead to a major non-healing wound. There is a great variability in the risk of developing radiation side effects. In part, this can be ascribed to differences in treatment and in patient characteristics (68). However, the pathophysiology of wound healing in the radiated skin is for the most part only theoretical. It is beyond controversy that histopathological changes like impaired neovascularization and excessive fibrosis are essential causes, particularly with regard to the late side effects of radiotherapy. By the same token, it is clear that many of the observed changes, in the side effects are elicited by the activation or deactivation of growth factors and cytokines. Ionizing radiation changes their interactions and cascades. IL-1, which is primarily secreted by macrophages and keratinocytes, is also directly activated by ionizing radiation. IL-1 stimulates keratinocytes and fibroblasts as well as MMPs. It has been demonstrated that ionizing radiation is able to induce the release of TNF- $\alpha$ by different cell types. TNF- $\alpha$ is a potent activator of neutrophils, stimulates the proliferation of fibroblasts and induces the synthesis of MMPs. Decreased proliferation, impaired angiogenesis, and persistently high concentrations of MMPs were recently seen in an in vitro analysis of radiation-induced dermal wounds (71-73). The impact that growth factors and cytokines have in radiationinduced wound healing disorders is obvious. Further studies are necessary, but in the last few years it has become clear that there is an important and direct genetic component (74-76).

These correlations shall be outlined using fibrosis as the example. Changes in collagen metabolism apparently have an important role in fibrosis formation. Elevated TGF- $\beta 1$ levels are correlated with an increased risk of fibrosis. As collagen is the major structural protein and composes $70-80 \%$ of the dry weight of the skin, modulation of skin collagen metabolism by therapeutic irradiation has clinical importance. Skin collagen, synthesized by fibroblasts, is comprised from $80-85 \%$ type I and of $10-15 \%$ type III collagen (77-79). Single nucleotide polymorphisms (SNPs) account for most of the known genetic variations between individuals and are usually defined as polymorphisms in which the minor variant (allele) is present in at least $1 \%$ of a given population. SNPs can affect protein function by altering the amino acid composition or by affecting various aspects of transcriptional and translational control (80).

\section{Prevention and therapy of skin reactions}

The prevention and treatment procedures of early and late skin reactions to radiotherapy are particularly and categorically polypragmatic. The course of action can be divided into five sections.

Radiation delivery methods. Fractionation allows the delivery of a larger total dose of radiation to the cancer than would be possible as a single dose. Most radiation treatments are delivered daily, 5 days a week (81). Hyperfractionation means to reduce the $24-\mathrm{h}$ interval to $6-8 \mathrm{~h}$. Conformal radiation is another possible solution for reducing the dose to normal tissue. A computer performs a three-dimensional (3D) transformation of the CT slices and creates a digitally reconstructed radiograph (DRR). The beams are very precisely directed and the nearby normal tissue receives less doses (82). Intensity modulated radiation therapy (IMRT) is an advanced type of conformal radiation. It allows radiation to be more exactly shaped to fit the tumor. With IMRT the radiation beam can be broken up into many beamlets, and the intensity of each beamlet can be adjusted individually (83).

General and supportive recommendations. Literature suggests that most advice given to patients being treated with radiation therapy is based on expert opinion rather than on reporting study results (84). The main recommendation is that gentle skin and hair washing should be unrestricted. The quality and quantity of studies evaluating the use of topical and oral agents did not allow for specific recommendations in those areas. There has been some evidence suggesting that the use of certain topical steroid creams and topical acid creams has a 
radioprotective effect, but more studies are needed to support recommendations. There has been limited evidence to support the use of sucralfate, Biafine cream, aloe vera, chamomile cream or dressings for the prevention of acute radiation skin reactions (85).

Protective medical therapy. Sucrose octasulfate (SOS) is believed to stabilize FGFs and to stimulate regenerative processes of the skin. This agent, in combination with growth factors, has been the subject of several research studies. Rashid et al (1999) showed that co-administration of bFGF and sucralfate markedly facilitates the rat dorsal flap survivability by enhancing bFGF expression and angiogenesis (86). Yeh et al concluded that the SOS structure provides an attractive template for the development of easily synthesized SOS-related heparin agonists and antagonists that may hold therapeutic potential (87). Amifostine was originally indicated to reduce the cumulative renal toxicity from cisplatin in non-small cell lung cancer. Protection against radiation-induced dermatitis was analyzed retrospectively in patients with pelvic tumors who were treated with radiotherapy. The studies showed hopeful results (88).

Medical therapy in radiogenic skin damage. Bolderston et al described a lack of strong evidence regarding the management of radiation therapy-related wounds such as moist desquamation (84). Steroid creams, sucralfate cream and various dressings were examined, but their comparisons were limited by use of unequal treatment parameters. The best available wound care is implicitly required on the management of radiation therapyrelated wounds, such as moist desquamation. Further research is warranted to support changing the practice. At the moment, no established recommendation can be made and only expert opinions can be given.

Surgical treatments. The best available wound care includes surgical treatments. Each surgical procedure presents great challenges because of unique difficulties in judgement and technique. Procedures to remove the damaged structures and to affect a sound wound closure must be varied as the involved site and the extent of the pathology dictate. A multistaged and deliberated approach is absolutely necessary because all the best intentions of the surgeon will not excuse culpability in the case of a deleterious result. Of course, these multistage, deliberate approaches are aimed to each kind of surgery, but in irradiated tissue the problems occur much more frequently and faster than in non-irradiated tissue. Inadequate resection may very quickly result in progressive pathological changes. Unnecessary exposure of important structures and further necrosis of the bone and cartilage are typical complications as well as secondary hemorrhage, progressive infection and progressive necrosis. Additionally, the surgeon should always keep in mind that the reason for a non-healing ulcer may also be a result of malignancy. The basic prerequisite is to remove altered tissue to the level of good, minute blood supply. After this, thin split-skin grafts can be useful to close and clean up a wound, even though more definite flaps are planned. In the acute stage, additional surgical procedures should not be performed in the inflamed tissue. In later stages operations can be performed and the skin can be expected to heal and provide good stable coverage. It is important to maintain the patient in a good general condition, with e.g., normal hemoglobin and to improve his general nutrition for better wound healing (69). A percutaneous endoscopic gastrostomy should be considered in the early stages of the disease, especially in patients with dysphagia. Depending on the severity, the reconstructive ladder is from simple closures of the wound, skin grafts, to local and distant flaps and to microvascular-free flaps. The suturing technique should ensure as little trauma to the skin as possible, with everted wound edges and infection prophylaxis. Marginal skin tension in the wound can induce dehiscence with infection and necrosis.

Skin grafts and flaps. Both types of skin grafts, split-skin grafts and full-thickness skin grafts are transfers of tissue without its own blood supply (89). Therefore, survival of the graft depends entirely on the blood supply from the recipient site. The grafts contain the epidermis and only a portion of the dermis. The dermis left behind at the donor site contains hair follicles and sebaceous glands, both of which contain epidermal cells which gradually proliferate out to form a new layer of epidermis. The donor site may be painful and vulnerable to infection. For more extensive tissue loss, a fullthickness skin graft, which includes the entire thickness of the skin, may be necessary. Full-thickness grafts contract less and the donor site heals much better than the donor site of a splitskin graft. However, full-thickness grafts are more at risk to undergo necrosis. Flaps should be used when a simple skin graft will not be adequate e.g., for coverage of exposed or potentially exposed vital structures or for filling out contours. By definition there are distinctions between axial pattern flaps (flaps with named blood supplies), random flaps (unnamed blood supply) and muscle, musculocutaneous (muscle and skin), fasciocutaneous (fascia and skin), osseous (bone) and osseocutaneous (bone and skin) flaps (90). Besides this definition there yet exist various different classifications which typically include the type of blood supply, type of tissue to be transferred and location of donor site $(91,92)$. Local flaps closely match the defect in color and quality and are characterized as skin from the periphery of the defect site, which is mobilized and repositioned to fill the deficit. Various forms of local flaps can be designed (93). The flap designs include rotation, transposition and interpolation. Advancement flaps include single pedicle, bipedicle and V-Y flaps. Distant flaps may be either pedicled or free (94). Pedicled skin flaps provide a method of transferring skin with an intact blood supply to a remote site (90). Once the flap develops a source of blood supply form its new bed, the vascular pedicle can be detached. Free flaps are physically detached from their native blood supply and then reattached to vessels at the recipient site. This anastomosis typically is performed using a microscope, and thus is known as a microsurgical technique $(95,96)$.

\section{Prospects}

Radiation therapy techniques. Since the last century, when radiation therapy was in its infancy as an established treatment for cancer, there has been great progress in the minimization of the therapeutic dose. In order to further minimize the side effects, the dose of ionizing radiation affecting non-cancerous tissue has to be further downsized. Better possibilities of 
planning with improved preoperative imaging and enhanced delivery techniques, like IMRT, show great promise. Further development and refinement of particle therapy is a great challenge, but at the same time auspicious. This also applies to targeted radionuclide therapy with the development of precise radiolabeled carriers.

Growth factors. Knowledge about the co-actions of these communicating molecules increases constantly (97-99). However, growth factors and cytokines are pleiotropic and act on multiple cells and tissues producing a wide range of effects, so that a systemic administration of growth factors or antibodies implies unforeseeable dangers. The topical application of a single growth factor may have only a transient effect. Proteolytic enzymes in the wound exudates tend to lyse topically applied growth factors. The final diffusion into the wound tissue of the active protein, which remains on the wound bed after these interactions, is hence predictably low. Furthermore, wound healing is not only dependent on the growth factor environment, but also on other parameters such as wound care, infection, tissue oxygen level and nutrition. Yet, growth factors are limited in clinical use and to this day no topically or systemic therapies for irradiated skin using growth factors have been established. Nonetheless, by increasing our understanding of radiation-induced dermal injury and by studying new cytokine interventions (e.g., antibodies, therapy with antagonistic growth factors) as well as by identification of more growth factors involved in this abnormal wound healing may provide possibilities to improve skin healing after radiation therapy.

Gene therapy. Gene therapy is generally defined as the treatment of hereditary genetic failures and the resulting defects in metabolic key functions. It requires the exact knowledge and localization of relevant genes involved in the metabolic process (100). The detection and use of SNP of growth factors might bring a new approach, but clinical use is a distant prospect. Another possibility for gene therapy of the skin is the somatic gene therapy. This implies the direct introduction of DNA into the tissue (101). The skin is an ideal candidate for such genetic manipulations because it is easily accessible, and it is therefore easy to transfect with genetic material and to monitor for adverse reactions. The epidermis has a high turnover rate, which is an ideal environment for most gene transfer methods. The predominant cells of the skin, fibroblasts and keratinocytes, are readily harvested and cultured. Gene delivery systems are called vectors (102). A distinction is drawn between virusdependent (transduction) and virus-independent (transfection) gene transfer $(103,104)$. Both can be carried out in vivo, whereby genes are delivered directly to target cells, or in vitro, in which cells are removed from the tissue, genetically modified, and implanted back into the donor tissue. Transduction techniques are performed using recombinant adenoviruses, adenoassociated viruses, retroviruses and the recombinant herpes simplex viruses. However, viral infection associated toxicity, immunological compromise and possible mutagenetic or carcinogenic effects make this approach potentially dangerous. The transfection techniques employed are direct injection, transfection with liposomes (lipofection), electroporation, particle bombardement (gene-gun) and antisense oligonuleotide delivery (105). The key benefits of these techniques are the ability to package relatively large amounts of genetic material and to introduce it with low immunogenicity. Their disadvantages are non-specific targeting and low efficiency, which necessitates repeated treatments. However, this last disadvantage is a welcome attribute in wound treatment, because the termination of the gene effect is desirable after the completion of the healing process. Non-viral gene delivery is easy, simple, direct, and inexpensive and does not require in vitro manipulation. Nevertheless, among these techniques, the optimal delivery system has not yet been identified (106).

\section{Conclusions}

Despite great progress in radiation therapy techniques, severely disturbed wound healing still remains a common side effect. In particular, fibrosis, induced by ionizing radiation, remains a tremendous challenge to each surgeon. There has also been great progress in understanding the fundamental principles of normal and disturbed wound healing. Somatic gene therapy may be the most promising approach for avoiding or healing irradiated tissue. However, intensive further investigation in all topics is indispensable.

\section{References}

1. Nuyts S: Defining the target for radiotherapy of head and neck cancer. Cancer Imaging 7 Spec No A: S50-S55, 2007.

2. Sitton E: Early and late radiation-induced skin alterations. Part I: Mechanisms of skin changes. Oncol Nurs Forum 19: 801-807, 1992.

3. Dorr W and Hendry JH: Consequential late effects in normal tissues. Radiother Oncol 61: 223-231, 2001.

4. Bernstein EF, Sullivan FJ, Mitchell JB, Salomon GD and Glatstein E: Biology of chronic radiation effect on tissues and wound healing. Clin Plast Surg 20: 435-453, 1993.

5. Collen EB and Mayer MN: Acute effects of radiation treatment: skin reactions. Can Vet J 47: 931-935, 2006

6. Habel DW: Surgical complications in irradiated patients. Arch Otolaryngol 82: 382-386, 1965.

7. Neta R: Modulation of radiation damage by cytokines. Stem Cells 15 (Suppl 2): S87-S94, 1997.

8. Hom DB, Unger GM, Pernell KJ and Manivel JC: Improving surgical wound healing with basic fibroblast growth factor after radiation. Laryngoscope 115: 412-422, 2005.

9. Adamietz IA: Radiotherapy. Front Radiat Ther Oncol 42: 164-172, 2010.

10. Gerber DE and Chan TA: Recent advances in radiation therapy. Am Fam Physician 78: 1254-1262, 2008.

11. Minniti G, Amichetti M and Enrici RM: Radiotherapy and radiosurgery for benign skull base meningiomas. Radiat Oncol 4: 42, 2009.

12. Thomas MR: Brachytherapy: here today, gone tomorrow? Heart 91 (Suppl 3): iii32-iii34, 2005.

13. Kassis AI: Therapeutic radionuclides: biophysical and radiobiologic principles. Semin Nucl Med 38: 358-366, 2008.

14. Ward JF: DNA damage produced by ionizing radiation in mammalian cells: identities, mechanisms of formation, and reparability. Prog Nucleic Acid Res Mol Biol 35: 95-125, 1988.

15. Alsner J, Andreassen CN and Overgaard J: Genetic markers for prediction of normal tissue toxicity after radiotherapy. Semin Radiat Oncol 18: 126-135, 2008.

16. Bentzen SM and Overgaard M: Relationship between early and late normal-tissue injury after postmastectomy radiotherapy. Radiother Oncol 20: 159-165, 1991.

17. Perona R and Sanchez-Perez I: Control of oncogenesis and cancer therapy resistance. Br J Cancer 90: 573-577, 2004.

18. Holscher T, Bentzen SM and Baumann M: Influence of connective tissue diseases on the expression of radiation side effects: a systematic review. Radiother Oncol 78: 123-130, 2006. 
19. Brizel DM, Sibley GS, Prosnitz LR, Scher RL and Dewhirst MW: Tumor hypoxia adversely affects the prognosis of carcinoma of the head and neck. Int J Radiat Oncol Biol Phys 38: 285-289, 1997.

20. Harrison LB, Chadha M, Hill RJ, Hu K and Shasha D: Impact of tumor hypoxia and anemia on radiation therapy outcomes. Oncologist 7: 492-508, 2002.

21. Hansen AE, Kristensen AT, Law I, Jorgensen JT and Engelholm SA: Hypoxia inducible factors-regulation and comparative aspects in tumourigenesis. Vet Comp Oncol 9: 16-37, 2011

22. Smets EM, Garssen B, Schuster-Uitterhoeve AL and De Haes JC: Fatigue in cancer patients. Br J Cancer 68: 220-224, 1993.

23. Robinson DW: Surgical problems in the excision and repair of radiated tissue. Plast Reconstr Surg 55: 41-49, 1975.

24. Chabchoub I, Gharbi O, Remadi S, et al: Postirradiation osteosarcoma of the maxilla: a case report and current review of literature. J Oncol 2009: 876138, 2009.

25. Tahir M, Hendry P, Baird L, Qureshi NA, Ritchie D and Whitford P: Radiation induced angiosarcoma a sequela of radiotherapy for breast cancer following conservative surgery. Int Semin Surg Oncol 3: 26, 2006.

26. Frieben A: Demonstration eines Cancroids des rechten Handrückens, das sich nach langandauernder Einwirkung von Röntgenstrahlen entwickelt hatte. Fortschr Röntenstr 6: 106-111, 1902 .

27. Knighton DR, Hunt TK, Thakral KK and Goodson WH III: Role of platelets and fibrin in the healing sequence: an in vivo study of angiogenesis and collagen synthesis. Ann Surg 196: 379-388, 1982.

28. Mazzucco L, Borzini P and Gope R: Platelet-derived factors involved in tissue repair-from signal to function. Transfus Med Rev 24: 218-234, 2010.

29. Nurden AT, Nurden P, Sanchez M, Andia I and Anitua E: Platelets and wound healing. Front Biosci 13: 3532-3548, 2008.

30. Oncul O, Yildiz S, Gurer US, et al: Effect of the function of polymorphonuclear leukocytes and interleukin-1 beta on wound healing in patients with diabetic foot infections. J Infect 54: 250-256, 2007.

31. Ghosh K, Ren XD, Shu XZ, Prestwich GD and Clark RA Fibronectin functional domains coupled to hyaluronan stimulate adult human dermal fibroblast responses critical for wound healing. Tissue Eng 12: 601-613, 2006.

32. Eming SA, Krieg T and Davidson JM: Inflammation in wound repair: molecular and cellular mechanisms. J Invest Dermatol 127: 514-525, 2007.

33. Weiss SJ: Tissue destruction by neutrophils. N Engl J Med 320: 365-376, 1989.

34. Gieringer M, Elliott K, Gosepath J and Naim R: Keloids: fundamental principles and prospects (Review). Mol Med Rep 3: $13-20,2010$.

35. Stadelmann WK, Digenis AG and Tobin GR: Physiology and healing dynamics of chronic cutaneous wounds. Am J Surg 176 S26-S38, 1998

36. Im AR, Park Y and Kim YS: Isolation and characterization of chondroitin sulfates from sturgeon (Acipenser sinensis) and thei effects on growth of fibroblasts. Biol Pharm Bull 33: 1268-1273, 2010.

37. Campbell NE, Kellenberger L, Greenaway J, Moorehead RA, Linnerth-Petrik NM and Petrik J: Extracellular matrix proteins and tumor angiogenesis. J Oncol 2010: 586905, 2010.

38. Sevilla C, Dalecki D and Hocking D: Extracellular matrix fibronectin stimulates the self-assembly of microtissues on native collagen gels. Tissue Eng Part A 16: 3805-3819, 2010.

39. Dereure O: Hyaluronic acid and immunity. Ann Dermatol Venereol 137 (Suppl 1): S26-S29, 2010 (In French).

40. Muller K and Meineke V: Radiation-induced alterations in cytokine production by skin cells. Exp Hematol 35: 96-104, 2007.

41. Levenson SM, Geever EF, Crowley LV, Oates JF III, Berard CW and Rosen H: The healing of rat skin wounds. Ann Surg 161: 293-308, 1965

42. Hayden DM, Forsyth C and Keshavarzian A: The role of matrix metalloproteinases in intestinal epithelial wound healing during normal and inflammatory states. J Surg Res: Mar 26, 2010 (Epub ahead of print)

43. Grazul-Bilska AT, Johnson ML, Bilski JJ, Redmer DA, Reynolds LP, Abdullah A and Abdullah KM: Wound healing: the role of growth factors. Drugs Today (Barc) 39: 787-800, 2003

44. Rumalla VK and Borah GL: Cytokines, growth factors, and plastic surgery. Plast Reconstr Surg 108: 719-733, 2001.
45. Naim R, Chang RC, Alfano SS, et al: Targeting TGF-betal increases hepatocyte growth factor (HGF/SF) levels in external auditory canal cholesteatoma (EACC) epithelial cell culture. Regul Pept 130: 75-80, 2005

46. Matsuu-Matsuyama M, Nakashima M, Shichijo K, Okaichi K, Nakayama T and Sekine I: Basic fibroblast growth factor suppresses radiation-induced apoptosis and TP53 pathway in rat small intestine. Radiat Res 174: 52-61, 2010.

47. Shweiki D, Itin A, Soffer D and Keshet E: Vascular endothelial growth factor induced by hypoxia may mediate hypoxia-initiated angiogenesis. Nature 359: 843-845, 1992.

48. Han YF, Han YQ, Pan YG, Chen YL and Chai JK: Transplantation of microencapsulated cells expressing VEGF improves angiogenesis in implanted xenogeneic acellular dermis on wound. Transplant Proc 42: 1935-1943, 2010.

49. Bock O, Yu H, Zitron S, Bayat A, Ferguson MW and Mrowietz U: Studies of transforming growth factors beta 1-3 and their receptors I and II in fibroblast of keloids and hypertrophic scars. Acta Derm Venereol 85: 216-220, 2005

50. Schultz G, Rotatori DS and Clark W: EGF and TGF-alpha in wound healing and repair. J Cell Biochem 45: 346-352, 1991

51. Buckmire MA, Parquet G, Greenway S and Rolandelli RH: Temporal expression of TGF-beta1, EGF, and PDGF-BB in a model of colonic wound healing. J Surg Res 80: 52-57, 1998.

52. Roberts AB, Sporn MB, Assoian RK, et al: Transforming growth factor type beta: rapid induction of fibrosis and angiogenesis in vivo and stimulation of collagen formation in vitro. Proc Natl Acad Sci USA 83: 4167-4171, 1986.

53. Kaklamani VG and Pasche B: Role of TGF-beta in cancer and the potential for therapy and prevention. Expert Rev Anticancer Ther 4: 649-661, 2004.

54. Colwell AS, Yun R, Krummel TM, Longaker MT and Lorenz HP: Keratinocytes modulate fetal and postnatal fibroblast transforming growth factor-beta and Smad expression in co-culture. Plast Reconstr Surg 119: 1440-1445, 2007.

55. Shack RB: Management of radiation ulcers. South Med J 75 : 1462-1466, 1982

56. Wang L, Kwak JH, Kim SI, He Y and Choi ME: Transforming grow th factor-betal stimulates vascular endothelial growth factor 164 via mitogen-activated protein kinase kinase 3-p38alpha and p38delta mitogen-activated protein kinase-dependent path-way in murine mesangial cells. J Biol Chem 279: 33213-33219, 2004.

57. Ishikawa $\mathrm{T}$, Terai $\mathrm{H}$ and Kitajima T: Production of a biologically active epidermal growth factor fusion protein with high collagen affinity. J Biochem 129: 627-633, 2001.

58. Haisa M, Okochi $\mathrm{H}$ and Grotendorst GR: Elevated levels of PDGF alpha receptors in keloid fibroblasts contribute to an enhanced response to PDGF. J Invest Dermatol 103: 560-563, 1994.

59. Ross R, Raines EW and Bowen-Pope DF: The biology of plateletderived growth factor. Cell 46: 155-169, 1986.

60. Bernstein EF, Harisiadis L, Salomon GD, et al: Healing impairment of open wounds by skin irradiation. J Dermatol Surg Oncol 20: 757-760, 1994

61. Soo C, Hu FY, Zhang X, et al: Differential expression of fibromodulin, a transforming growth factor-beta modulator, in fetal skin development and scarless repair. Am J Pathol 157: 423-433, 2000.

62. Hsu M, Peled ZM, Chin GS, Liu W and Longaker MT: Ontogeny of expression of transforming growth factor-beta 1 (TGF-beta 1), TGF-beta 3, and TGF-beta receptors I and II in fetal rat fibroblasts and skin. Plast Reconstr Surg 107: 1787-1794, 2001

63. Furlong RA, Takehara T, Taylor WG, Nakamura T and Rubin JS: Comparison of biological and immunochemical properties indicates that scatter factor and hepatocyte growth factor are indistinguishable. J Cell Sci 100: 173-177, 1991.

64. Conway K, Ruge F, Price P, Harding KG and Jiang WG: Hepatocyte growth factor regulation: an integral part of why wounds become chronic. Wound Repair Regen 15: 683-692, 2007.

65. Zhu G, Huang L, Song M, et al: Overexpression of hepatocyte growth factor in smooth muscle cells regulates endothelial progenitor cells differentiation, migration and proliferation. Int $\mathbf{J}$ Cardiol 138: 70-80,2010.

66. Schonfelder U, Abel M, Wiegand C, Klemm D, Elsner P and Hipler UC: Influence of selected wound dressings on PMN elastase in chronic wound fluid and their antioxidative potential in vitro. Biomaterials 26: 6664-6673, 2005

67. Palolahti M, Lauharanta J, Stephens RW, Kuusela P and Vaheri A Proteolytic activity in leg ulcer exudate. Exp Dermatol 2: 29-37, 1993. 
68. Olascoaga A, Vilar-Compte D, Poitevin-Chacon A and ContrerasRuiz J: Wound healing in radiated skin: pathophysiology and treatment options. Int Wound J 5: 246-257, 2008.

69. McLean AS: Early adverse effects of radiation. Br Med Bull 29: 69-73, 1973.

70. Behrends U, Peter RU, Hintermeier-Knabe R, et al: Ionizing radiation induces human intercellular adhesion molecule-1 in vitro. J Invest Dermatol 103: 726-730, 1994.

71. Hallahan DE, Spriggs DR, Beckett MA, Kufe DW and Weichselbaum RR: Increased tumor necrosis factor alpha mRNA after cellular exposure to ionizing radiation. Proc Natl Acad Sci USA 86: 10104-10107, 1989.

72. Sherman ML, Datta R, Hallahan DE, Weichselbaum RR and Kufe DW: Regulation of tumor necrosis factor gene expression by ionizing radiation in human myeloid leukemia cells and peripheral blood monocytes. J Clin Invest 87: 1794-1797, 1991.

73. Goessler UR, Bugert P, Kassner S, et al: In vitro analysis of radiation-induced dermal wounds. Otolaryngol Head Neck Surg 142: 845-850, 2010.

74. West CM, Elliott RM and Burnet NG: The genomics revolution and radiotherapy. Clin Oncol (R Coll Radiol) 19: 470-480, 2007.

75. Fernet $\mathrm{M}$ and Hall J: Genetic biomarkers of therapeutic radiation sensitivity. DNA Repair (Amst) 3: 1237-1243, 2004.

76. Riekki R, Jukkola A, Sassi ML, Hoyhtya M, Kallioinen M, Risteli J and Oikarinen A: Modulation of skin collagen metabolism by irradiation: collagen synthesis is increased in irradiated human skin. Br J Dermatol 142: 874-880, 2000.

77. Riekki R, Harvima IT, Jukkola A, Risteli J and Oikarinen A The production of collagen and the activity of mast-cell chymase increase in human skin after irradiation therapy. Exp Dermatol 13: 364-371, 2004

78. Autio P, Saarto T, Tenhunen M, Elomaa I, Risteli J and Lahtinen T: Demonstration of increased collagen synthesis in irradiated human skin in vivo. Br J Cancer 77: 2331-2335, 1998.

79. Popanda O, Marquardt JU, Chang-Claude J and Schmezer P Genetic variation in normal tissue toxicity induced by ionizing radiation. Mutat Res 667: 58-69, 2009.

80. Kishore U, Bernal AL, Kamran MF, Saxena S, Singh M, Sarma PU, Madan T and Chakraborty T: Surfactant proteins SP-A and SP-D in human health and disease. Arch Immunol Ther Exp (Warza) 53: 399-417.

81. Barendsen GW: Dose fractionation, dose rate and iso-effect relationships for normal tissue responses. Int J Radiat Oncol Biol Phys 8: 1981-1997, 1982.

82. Yu CX, Amies CJ and Svatos M: Planning and delivery of intensity-modulated radiation therapy. Med Phys 35: 5233-5241, 2008

83. Nath SK, Simpson DR, Rose BS and Sandhu AP: Recent advances in image-guided radiotherapy for head and neck carcinoma. J Oncol 2009: 752135, 2009.

84. Bolderston A, Lloyd NS, Wong RK, Holden L and RobbBlenderman L: The prevention and management of acute skin reactions related to radiation therapy: a systematic review and practice guideline. Support Care Cancer 14: 802-817, 2006.

85. Bostrom A, Lindman $\mathrm{H}$, Swartling C, Berne B and Bergh J: Potent corticosteroid cream (mometasone furoate) significantly reduces acute radiation dermatitis: results from a double-blind, randomized study. Radiother Oncol 59: 257-265, 2001.

86. Rashid MA, Akita S, Razzaque MS, et al: Coadministration of basic fibroblast growth factor and sucrose octasulfate (sucralfate) facilitates the rat dorsal flap survival and viability. Plast Reconstr Surg 103: 941-948, 1999.

87. Yeh BK, Eliseenkova AV, Plotnikov AN, et al: Structural basis for activation of fibroblast growth factor signaling by sucrose octasulfate. Mol Cell Biol 22: 7184-7192, 2002.
88. Kouvaris J, Kouloulias V, Kokakis J, Matsopoulos G, Myrsini B and Vlahos L: The cytoprotective effect of amifostine in acute radiation dermatitis: a retrospective analysis. Eur J Dermatol 12: 458-462, 2002.

89. Adams DC and Ramsey ML: Grafts in dermatologic surgery: review and update on full- and split-thickness skin grafts, free cartilage grafts, and composite grafts. Dermatol Surg 31: 1055-1067, 2005.

90. McGregor IA and Morgan G: Axial and random pattern flaps. Br J Plast Surg 26: 202-213, 1973.

91. Weum S, De Weerd L, Klein S and Hage JJ: Soft tissue defects treated with perforator flaps. Tidsskr Nor Laegeforen 128: 313-315, 2008 (In Norwegian)

92. Chu EA and Byrne PJ: Local flaps I: bilobed, rhombic, and cervicofacial. Facial Plast Surg Clin North Am 17: 349-360, 2009.

93. Issing PR, Kempf HG, Heppt W, Schonermark M and Lenarz T: Reconstructive surgery in the head-neck area with regional and free tissue transfer. Laryngorhinootologie 75: 476-482, 1996 (In German).

94. El Marakby HH: The reliability of pectoralis major myocutaneous flap in head and neck reconstruction. J Egypt Natl Canc Inst 18: 41-50, 2006.

95. Krag C, De Rose G, Lyczakowski T, Freeman CR and Shapiro SH: Free flaps and irradiated recipient vessels: an experimental study in rabbits. Br J Plast Surg 35: 328-336, 1982.

96. Mulholland S, Boyd JB, McCabe S, Gullane P, Rotstein L, Brown D and Yoo J: Recipient vessels in head and neck microsurgery: radiation effect and vessel access. Plast Reconstr Surg 92: 628-632, 1993.

97. Tattini C, Manchio J, Zaporojan V, Carderelli G, Bonassar L, Spangenberger A and Weinzweig J: Role of TGF-beta and FGF in the treatment of radiation-impaired wounds using a novel drug delivery system. Plast Reconstr Surg 122: 1036-1045, 2008.

98. Fuks Z, Persaud RS, Alfieri A, et al: Basic fibroblast growth factor protects endothelial cells against radiation-induced programmed cell death in vitro and in vivo. Cancer Res 54: 2582-2590, 1994

99. Payne WG, Ochs DE, Meltzer DD, Hill DP, Mannari RJ, Robson LE and Robson MC: Long-term outcome study of growth factor-treated pressure ulcers. Am J Surg 181: 81-86, 2001.

100. Levy RJ, Goldstein SA and Bonadio J: Gene therapy for tissue repair and regeneration. Adv Drug Deliv Rev 33: 53-69, 1998.

101. Matrai J, Chuah MK and van den Driessche T: Preclinical and clinical progress in hemophilia gene therapy. Curr Opin Hematol 17: 387-392, 2010

102. Teschendorf C, Emons B, Muzyczka N, Graeven U and Schmiegel W: Efficacy of recombinant adeno-associated viral vectors serotypes 1,2 , and 5 for the transduction of pancreatic and colon carcinoma cells. Anticancer Res 30: 1931-1935, 2010

103. Erlwein O and McClure MO: Progress and prospects: Foamy virus vectors enter a new age. Gene Ther 17: 1423-1429, 2010.

104. Jeschke MG, Herndon DN, Baer W, Barrow RE and Jauch KW: Possibilities of non-viral gene transfer to improve cutaneous wound healing. Curr Gene Ther 1: 267-278, 2001.

105. Dickens S, van den BS, Hendrickx B, Verdonck K, Luttun A and Vranckx J: Non-viral gene therapy strategies for keratinocytes, fibroblasts and endothelial progenitor cells for ex vivo gene transfer to skin wounds. Tissue Eng Part C Methods 16: 1601-1608, 2010.

106. Branski LK, Pereira CT, Herndon DN and Jeschke MG: Gene therapy in wound healing: present status and future directions. Gene Ther 14: 1-10, 2007. 